\title{
Os Fatores Motivacionais de Escolha do Ensino a Distância: uma Abordagem sobre um Polo de Apoio Presencial de uma Instituição de Ensino Superior
} The Motivational Factors of Choice of Distance Education: an Approach

\section{Mara Aparecida Barnaski Fagundes ${ }^{1 *}$ \\ Jorge Oneide Sausen ${ }^{1}$ \\ Eusélia Pavaglio Vieira1}

${ }^{1}$ Universidade Regional do

Noroeste do Estado do Rio Grande

do Sul - UNIJUÍ. R. Do Comércio, 3000 -

Centro, ljuí - RS, Brasil.

*mara.fagundes@sou.unijui.edu.br

\section{Resumo}

Os fatores que motivam o estudante no ensino na modalidade a distância (EaD) vêm sendo amplamente debatidos na Educação. Nesse contexto, o presente artigo aborda a temática no que se refere aos fatores motivacionais na percepção dos estudantes de um polo de apoio presencial de uma universidade de ensino a distância, com o propósito de identificar o perfil demográfico e os fatores motivacionais que levaram esses alunos a optar por essa modalidade de ensino, levando-se em consideração a instituição de ensino e o polo de apoio presencial. Metodologicamente, realizou-se uma pesquisa exploratória, descritiva e quantitativa, utilizando-se da coleta de dados por meio da aplicação de um questionário aos estudantes, utilizando-se da escala Likert como opções de respostas, posteriormente analisadas com a utilização de métodos estatísticos que caracterizou a amostra com o cruzamento das informações. Os resultados apontam que os estudantes do polo de apoio presencial possuem as características demográficas de uma amostra jovem e em idade laboral, motivados pelo ensino a distância devido à flexibilidade de seus horários, os valores dos cursos e a oportunidade de promoção profissional na área em que atuam. Dessa forma, conclui-se que o principal fator motivacional para a escolha do ensino a distância são decisões pessoais que estão intimamente ligadas ao tempo e regidas pelas novas tendências do mercado de trabalho

Palavras-chave: Ensino a distância. Polos presenciais. Estudantes. Fatores motivacionais.

\section{(c) (i)}

Recebido 16/ 05/ 2020 Aceito 04/ 11/ 2020

Publicado 17/ $11 / 2020$

\section{COMO CITAR ESTE ARTIGO}

ABNT: FAGUNDES, M.A.B., SAUSEN, J. O.; VIEIRA, E. P. Os Fatores Motivacionais de Escolha do Ensino a Distância: Uma Abordagem Sobre um Polo de Apoio Presencial de uma Instituição de Ensino Superior. EaD em Foco, v. 10, n. 2, e1044, 2020. doi: https://doi.org/10.18264/eadf.v10i2.1044 


\section{The Motivational Factors of Choice of Distance Education: a Approach of a Presential Suport Pole of a Higher Education Institution}

\section{Abstract}

The factors that motivate students in teaching in distance learning have been widely debated in the education. In this context, the present article approaches the theme with regard to motivational factors in the perception of students of a classroom support pole of a distance learning university, with the purpose of identifying the demographic profile and motivational factors that led these students to choose this type of teaching, taking into account the teaching institution and the classroom support center. Methodologically, an exploratory, descriptive and quantitative research was carried out, using data collection through the application of a questionnaire to students, using the Likert scale as answer options, later analyzed using statistical methods and characterized the sample with the crossing of the information. The results indicate that the students of the face-to-face support center, have demographic characteristics of a young and working-age sample, motivated by distance learning due to the flexibility of their schedules, the values of the courses and the opportunity for professional promotion in the area that act. Thus, it is concluded that the main motivational factor for choosing distance learning are personal decisions that are closely linked to time and governed by new trends in the labor market.

Keywords: Distance learning. Face-to-face centers. Students. Motivational facto.

\section{Introdução}

O ensino a distância (EaD) surge como um proporcionador de novos caminhos e experiências pedagógicas. O contexto de sala de aula virtual assume um novo design de espaço e tempo, onde emergem Ambientes Virtuais de Aprendizagem (AVA) aptos a acolher diferentes estudantes, modificando a disseminação de conhecimento e aprendizagem (MOLEIRINHO; MALHEIRO; MORGADO, 2013). Diante dessas mudanças, a modalidade de ensino a distância - com sua concepção de ensino mais aberta - é ofertada como uma inovação em termos de Educação, em virtude de características como a flexibilidade de seus programas, a agilidade dos seus mecanismos administrativos e, fundamentalmente, a ênfase na autonomia dos alunos em relação à escolha de locais e horários de estudo (RUSSO, 2016).

Levando-se em consideração esse processo, as exigências da economia sem fronteiras trouxeram mudanças radicais na convivência social, criando novos paradigmas para ajustar-se ao mercado de trabalho. É de onde vem a mudança no público geral das graduações. Hoje, aqueles que já haviam interrompido seus estudos, podem regressar ao processo de ensino e, em muitos casos, esse retorno tornou-se imperativo, a fim de manter os postos de trabalho em função das transformações tecnológicas evidenciadas. Assim, boa parcela desse público acaba optando pelo ensino a distância (ROLIM; SCARAMUZZA, 2016). Portanto, compreender a importância do ensino a distância auxilia no entendimento das relações entre os processos educacionais formativos e o mercado de trabalho.

Apesar das facilidades apresentadas pelo EaD, isso não basta para tornar as instituições e os polos de apoio presenciais (PAPs) atrativos. A necessidade de avaliar os fatores motivacionais desses estudantes 
faz parte das estratégias de captação de novos alunos. Diante desse contexto, o objeto de análise desta pesquisa são os estudantes de um polo de apoio presencial (PAP), de uma universidade situada em uma cidade da região Noroeste do Estado do Rio Grande do Sul. O polo de apoio presencial é o local devidamente credenciado pelo Ministério da Educação, próprio para o desenvolvimento descentralizado de atividades pedagógicas e administrativas relativas aos cursos e programas ofertados a distância. É no polo que o estudante possui as atividades de tutoria presencial, biblioteca, laboratórios, avaliações (provas, exames, etc.). Portanto, o PAP torna possível uma interação entre a universidade, que se encontra geograficamente distante, e o estudante.

A partir dessas premissas, faz-se necessário uma pesquisa, avaliando os estudantes à luz do comportamento do consumidor, uma vez que eles são os consumidores dos serviços do PAP e estão distribuídos entre os cursos de graduação e de pós-graduação. O comportamento do consumidor é um tema complexo e uma área interdisciplinar que envolve conceitos e ferramentas metodológicas de diferentes áreas do conhecimento, como a psicologia, a economia, a sociologia, a antropologia, a semiótica, a demografia e a história (TEIXEIRA, 2010). Segundo Mccarthy e Perreault (1997), muitas variáveis influenciam o comportamento de compra do consumidor e são diferentes para cada produto e/ou serviço e mercado-alvo. Assim, é preciso analisar os principais fatores que influenciam diretamente o comportamento do consumidor, como os fatores culturais, sociais, pessoais, psicológicos (MOURA, 2017) e os fatores de mercado ou econômicos.

Diante dessas considerações, pretendeu-se investigar os fatores motivacionais de escolha do ensino na modalidade EaD dos alunos de um polo de apoio presencial de uma universidade que oferece graduação e pós-graduação EaD, com vistas a gerar contribuições à instituição no apoio ao processo de definição de estratégias que possam potencializar a manutenção de alunos, como também a captação de novos alunos, com o foco de contribuir com o EaD e as melhorias de ensino. $\mathrm{O}$ artigo está estruturado com os preceitos teóricos que sustentaram a pesquisa, a metodologia da pesquisa adotada, os resultados obtidos e, por fim, as considerações finais do trabalho.

\section{Revisão da Literatura}

A literatura que sustenta a argumentação deste artigo está organizada em dois tópicos principais: 2.1 os pressupostos basilares do ensino a distância: abordando o uso das tecnologias e as mudanças do mercado de trabalho; 2.2 os fatores motivacionais dos estudantes que optam pelo EaD: sintetizando os fatores motivacionais dos estudantes.

\subsection{Os pressupostos basilares do ensino a distância}

O ensino a distância, como vemos nos dias atuais, começou a se desenhar na década de 1980, com o surgimento do microcomputador, trazendo transformações significativas no aprendizado. A aplicabilidade do computador tornou-se tão múltipla quanto variada, transitando por áreas distintas. Ao longo das últimas três décadas, é fácil perceber as transformações nos conceitos de aprendizagem, devido à diligência dos aspectos sociais difundidos pelos computadores e que impulsionaram a globalização, acelerando tecnologicamente a comunicação humana (ROLIM; SCARAMUZZA, 2016). Desta forma, a necessidade de estar ou não presente se vincula à necessidade social do aluno de querer aprender mais, de solucionar suas dúvidas e de se posicionar diante do conhecimento (RICARDO, 2019). O grande desafio foi evoluir das metodologias pedagógicas utilizadas, independentemente das tecnologias que as suportavam, construindo perspectivas educativas originadas por contextos sociais (MOLEIRINHO; MALHEIRO; MORGADO, 2013). Os contextos sociais estão relacionados, principalmente, ao mercado de trabalho, à industrialização e ao comportamento dos indivíduos. 
Dessa forma, quando visto pela óptica do comportamento, as exigências do mercado influenciaram e direcionaram as universidades privadas para modalidades mais competitivas, onde os estudantes são mantenedores dessas instituições, tornando o estudante um consumidor, pois, ao mesmo tempo em que consome um serviço, consome os produtos inclusos nesse serviço, o que torna o ambiente educacional proporcionador de um duplo comportamento do consumidor. Um deles é quando o estudante tem suas vontades e desejos atendidos sem prejuízo de sua aprendizagem e um curso consumindo um serviço básico de Educação; e o outro comportamento é quando o estudante usufrui de biblioteca, secretaria, infraestrutura, consumindo um serviço suplementar da Educação (SCHINAIDER; FAGUNDES; SCHINAIDER, 2016). E esta afirmação se torna basilar, tanto para o ensino EaD quanto para o ensino presencial.

Naturalmente, levando em consideração o comportamento dos indivíduos, o ensino a distância ganhou destaque em relação ao ensino presencial; a transmissão descentralizada do saber proporciona uma nova experiência aos estudantes e professores, e é capaz de alcançar um grande público, enquanto mantém operações de baixo custo (ROLIM; SCARAMUZZA, 2016), o que torna as mensalidades dessas universidades acessíveis diante das universidades privadas presenciais. Desse modo, pesquisadores acreditam que o ensino a distância apresenta uma resposta válida para uma abordagem de ensino superior mais equitativo, onde todos podem, de acordo com as suas motivações e necessidades, prosseguir os seus estudos, contribuindo assim para o seu próprio sentido de independência, integração e participação ativa na vida social (MOLEIRINHO; MALHEIRO; MORGADO, 2013), mesmo que as relações sociais se encontrem às margens dessa modalidade de ensino, sendo flexibilidade e otimização do tempo seus principais preceitos na justificativa de alcançarem um número significativo de alunos.

Os números da EaD se mostram crescentes desde o seu surgimento. Conforme o Censo da Educação Superior de 2019, ocorreu um aumento expressivo da modalidade a distância (18\%) em relação à modalidade presencial (2\%) (INEP, 2019). Um dado pertinente da pesquisa é o indicador de que a faixa etária dos alunos de cursos de ensino a distância é maior que a dos alunos de cursos presenciais. Enquanto em cursos presenciais a média de idade é de 26 anos, nos cursos a distância ela é de 33 anos. O percentual da população com ensino superior por faixa etária é $16 \%$ até 34 anos e $11 \%$ até 64 anos. Isso deixa evidente que o ensino a distância se tornou uma oportunidade mais relevante do que os cursos presenciais para pessoas mais velhas (ROLIM; SCARAMUZZA, 2016). Outro dado do censo são os percentuais de participação dos sexos no ensino a distância (INEP, 2018). As mulheres representam 12\% dos estudantes do ensino superior e os homens $11 \%$. Esses números se justificam, pois nos primeiros anos da modalidade no ensino superior, a mesma estava voltada basicamente para a formação de profissionais ligados às áreas de Educação, posto de trabalho ocupado predominantemente por mulheres, mas já é possível notar uma ampliação das áreas de concentração dos cursos, como é o caso das áreas da engenharia (ASSUMPÇÃO; HAMADA; CASTRO, 2018), predominantemente ocupadas por homens em seu campo de atuação.

\subsection{Os fatores motivacionais dos estudantes que optam pela EaD}

Além das características demográficas, o aluno que estuda na EaD possui características disciplinares e autogestão de seus estudos para conseguir cumprir as ações pedagógicas requeridas pelos cursos, que podem ser considerados como fatores motivacionais importantes. Os fatores motivacionais formam um modelo geral de comportamento nas quais influências externas (cultura, fatores demográficos, família, etc.) e internas (percepção, aprendizado, personalidade, emoções, atitudes, etc.) que levam à formação de uma autoimagem e um estilo de vida (HAWKINS; MOTHERSBAUGH; BEST, 2007). A principal influência externa é a cultura, pois ao crescer em uma sociedade, os seres humanos adquirem valores básicos, percepções, desejos e comportamentos - o que, segundo Kotler e Armstrong (2007), norteiam nossos hábitos de consumo e preferências ao longo da vida. Já a principal influência interna é a aprendizagem. A aprendizagem é o aspecto central do fator psicológico de motivação; por esse motivo, as ações pedagógicas movem seus esforços sempre para ensinar algo. 
O processo apresenta diversos fatores, como as diferenças individuais, as influências ambientais e os indicadores psicológicos, que podem afetar o comportamento (ENGEL; BLACKWELL; MINIARD, 2013), e são os mesmos quando inseridos no meio acadêmico. É um processo que oferece bens tangíveis; um exemplo disso se dá através dos materiais didáticos. Segundo Rolim e Scaramuzza (2016), os materiais devem oferecer possibilidades formativas dinâmicas, capazes de ampliar a liberdade do estudante para experimentar, testar e reelaborar o conhecimento, imprimindo significado concreto nas aplicações possíveis das competências a serem alcançadas, gerando assim percepções e mecanismos motivacionais. $O$ que vai ao encontro do que afirmam Kotler e Keller (2006), que a percepção da motivação depende de estímulos físicos e da relação desses estímulos com o ambiente e as condições internas da pessoa, para que receba essas influências de forma positiva, gerando uma escolha definitiva.

Desta maneira, estudos que evidenciam essas influências constatam que a flexibilidade proporcionada pela modalidade EaD foi a principal razão da escolha, por favorecer a conciliação entre os estudos e a rotina do estudante (SCHLIKMANN et al., 2008). Outro fator apontado pelos estudos de Souza (2012) verificou que o valor das mensalidades exerce forte influência sobre a opção da modalidade de ensino. Em outros estudos, Sun et al. (2008) afirmam que o ambiente virtual de aprendizagem oferecido pela EaD foi citado pela maioria dos universitários como motivação para estudarem nessa modalidade. O que evidencia que o estudante, no seu papel de consumidor, está sempre buscando no mercado algo que satisfaça suas necessidades e desejos (BINOTTO et al., 2014) e efetivando aprendizados.

Outros fatores que se constituem em motivações para os estudantes são a comodidade e a facilidade para aqueles que residem longe dos grandes centros urbanos e possuem uma extensa escala laboral. Os estudos de Peters (1989) sugerem que o ensino a distância é produto da sociedade industrial e de consumo. O autor comparou o ensino a distância com a produção industrial, identificando características comuns e afirmando que o sucesso desse tipo de ensino se explica pelos valores semelhantes aos da sociedade de consumo, onde "tempo é dinheiro" e grande proporcionador de bem-estar.

Portanto, quando se efetivam esses estudantes como consumidores, pode-se analisá-los pelas mesmas motivações de compra, em um mercado que cresce acentuadamente no país, em que a oferta por serviços e produtos torna as universidades concorrentes entre si, e, como em qualquer empresa, o interesse é a geração de lucro. Em suma, este comportamento, segundo Schiffman e Kanuk (2000), é influenciado por cinco fatores: mercadológicos, culturais, sociais, pessoais e psicológicos.

\section{Metodologia}

A pesquisa foi realizada por meio de uma abordagem exploratória e incide numa metodologia descritiva, sustentada pelos dados obtidos em uma investigação qualitativa (bibliografia) e quantitativa (survey), centrando-se em um estudo de campo, que constitui em uma instância provocadora do estudo de mediações que concentram a possibilidade de explicar a realidade concreta (FRANCO, 1990). Por esse motivo, possui como ambiente natural e fonte direta de dados o Polo de Apoio Presencial de uma instituição a distância situada na região Noroeste do Estado do Rio Grande do Sul. As pesquisas exploratórias são aquelas que buscam uma proximidade da realidade do objeto estudado e, segundo Berni e Fernandes (2012), são realizadas a partir das experiências pela observação livre dos fenômenos para chegar a proposições gerais, que é denominada de indutiva ou empirismo.

Por outro lado, as pesquisas descritivas, conforme Gil (1996), têm como objetivo a descrição de determinada população ou fenômeno ou estabelecimento de relações entre variáveis. A coleta de dados deu-se a partir de uma pesquisa quantitativa, em que o pesquisador observa o fenômeno de fora, sem se envolver com o objeto de pesquisa. Fazendo uso de variáveis objetivas e tangíveis de forma dedutiva com nenhum grau de subjetividade (VERGARA, 2009). O recurso utilizado foi o levantamento, ou survey, 
que tem como característica o interesse de produzir descrições quantitativas de uma população, fazendo uso de um instrumento predefinido (SOARES; ARDIGÓ; MARCOS FILHO, 2017). Esse tipo de questionário é baseado num interrogatório, sendo que, para esta pesquisa, foram realizadas perguntas acerca de seus dados demográficos e seu comportamento como estudante, escolha do curso e o envolvimento com a instituição, pelo ponto de vista de suas motivaç̃̃es como consumidores dos produtos e serviços oferecidos.

Antes da aplicação do questionário, foi realizado um teste-piloto com três estudantes pertencentes à mesma amostra da pesquisa. O objetivo foi avaliar aspectos funcionais, como pertinência, organização, clareza das questões, de modo a corrigir e melhorar eventuais problemas antes da aplicação definitiva (IRAOSSI, 2006). Após o teste-piloto, cerca de 218 questionários foram aplicados, sendo que apenas 112 retornaram respondidos. Desses, 11 foram anulados por não terem sido preenchidos corretamente e 101 foram considerados válidos. O período de pesquisa foi de 06 de julho de 2019 a 23 de setembro de 2019. Para medir as motivações dos estudantes, a escala utilizada foi a Likert, que, de acordo com Malhorta (2001), é considerada uma escala de medida com cinco categorias de respostas, que vão do discordo totalmente ao concordo totalmente, exigindo que os entrevistados indiquem um grau de concordância, com uma série de afirmações relacionadas aos objetos de estímulo. Assim, o questionário foi estruturado visando à padronização na coleta de dados. A análise dos dados foi realizada com o auxílio do software estatístico. Os procedimentos de análise utilizados foram: distribuição de frequência e análise das médias. Para a avaliação dos contrastes, foi utilizado o método SPSS 20.0 (Statistical Package for the Social Science). As tabelas inseridas no corpo do texto foram produzidas a partir dos dados pesquisados, seguindo-se o cruzamento desses para se alcançar os resultados e proporcionar aos estudantes da instituição uma tipologia quanto aos dados demográficos e suas predominâncias, traçando um perfil para os mesmos e os fatores motivacionais envolvidos no processo de escolha do ensino a distância.

\section{A Instituição e a Caracterização da Amostra}

A instituição atua desde o ano 2000 no ensino superior privado, sendo uma das pioneiras na modalidade de ensino a distância, atendendo alunos em mais de 500 polos de apoio presencial em todo o país. De acordo com os Referenciais de Qualidade para Educação Superior a Distância, no PAP são realizadas atividades presenciais, previstas em lei. Assim, o PAP é a porta de entrada dos estudantes na instituição. Quando caracteriza esses estudantes, a instituição consegue investir em processos pedagógicos para a arrecadação de novas matrículas e ampliação de seus negócios.

A idade dos entrevistados ficou entre 30 e 49 anos, obtendo uma representatividade de 59\%, características de uma amostra relativamente adulta e em idade laboral. 0 perfil desse estudante é o de quem costuma avaliar a flexibilidade do próprio curso EaD, pois, como ele possui um labor, o curso a distância facilita o progresso de seu ensino (SCHINAIDER; FAGUNDES; SCHINAIDER, 2016) sem prejudicar suas atividades de trabalho. Em relação ao gênero, o masculino representou 57\%, caracterizando uma amostra masculina mais representativa no PAP. Em relação ao estado civil, $48 \%$ da amostra relataram ser solteiros(as). Quanto à ocupação, 43\% disseram ser funcionários de empresas privadas, o que caracteriza que mais da metade dos estudantes trabalham e possuem renda. E quanto à renda, $71 \%$ responderam terem uma renda de até 3 salários-mínimos, justificando a procura por preços acessíveis.

Segundo dados do Resumo Técnico do Censo da Educação Superior (INEP, 2014), a participação feminina na Educação superior supera a masculina. Em cursos a distância, a participação feminina é ainda maior (ASSUMPÇÃO; HAMADA; CASTRO, 2018). Outros dados do Censo demonstram que os estudantes do ensino a distância, em sua maioria, são pessoas que possuem a chamada "experiência de vida acumulada", explicada por Peters (1989) como pessoas casadas e responsáveis pelo sustento da família. Para o autor, o ensino precisou ajustar-se à era pós-moderna e pós-industrial. Essas mudanças apareceram nos setores da sociedade com tecnologias mais individualizadas, tomadas de decisão mais descentralizadas e valores 
pessoais focados em qualidade de vida, realização, aprendizagem e interdependência. No entanto, no PAP, a maioria dos estudantes diverge desses dados e características de estilo de vida - o que demonstra a importância de se traçar esse perfil de estudante e se dedicar a ele para entender suas necessidades e expectativas (GONÇALVES, 2007).

Os dados referentes à caracterização da amostra estão descritos na Tabela 1.

Tabela 1: Características da amostra

\begin{tabular}{|c|c|c|}
\hline Faixa etária & Frequência & Porcentagem \\
\hline Abaixo de 18 anos & 1 & $1,00 \%$ \\
\hline Entre 18 e 29 anos & 36 & $35,60 \%$ \\
\hline Entre 30 e 49 anos & 60 & $59,40 \%$ \\
\hline Entre 50 e 69 anos & 4 & $4,00 \%$ \\
\hline Gênero & Frequência & Porcentagem \\
\hline Feminino & 43 & $42,60 \%$ \\
\hline Masculino & 58 & $57,40 \%$ \\
\hline Estado civil & Frequência & Porcentagem \\
\hline Solteiro(a) & 49 & $48,50 \%$ \\
\hline Casado(a) & 41 & $40,60 \%$ \\
\hline Outro & 9 & $8,90 \%$ \\
\hline União estável & 2 & $2,00 \%$ \\
\hline Ocupação & Frequência & Porcentagem \\
\hline Desempregado & 4 & $4,00 \%$ \\
\hline Estudante & 9 & $8,90 \%$ \\
\hline Funcionário público & 35 & $34,70 \%$ \\
\hline Funcionário empresa privada & 43 & $42,60 \%$ \\
\hline Empresário & 3 & $3,00 \%$ \\
\hline Autônomo & 7 & $6,90 \%$ \\
\hline Renda (salários mínimos) & Frequência & Porcentagem \\
\hline Até 3 salários & 72 & $71,30 \%$ \\
\hline Entre 4 a 6 salários & 23 & $22,80 \%$ \\
\hline Entre 7 a 9 salários & 5 & $5,00 \%$ \\
\hline Entre 10 a 15 salários & 1 & $1,00 \%$ \\
\hline
\end{tabular}

Fonte: Dados da pesquisa, 2019.

Segundo Kotler e Armstrong (2007), os comportamentos são influenciados por diferentes fatores, sejam culturais, sociais, pessoais, psicológicos ou mercadológicos. Por serem fatores muito amplos, são facilmente estudados em conjunto. Em virtude disso, pode-se realizar o cruzamento dos dados com a faixa etária dos respondentes e as motivações que os levaram a estudar na modalidade EaD. A avaliação foi ao encontro com os dados coletados no perfil demográfico. Uma vez que os respondentes estão na faixa etária dos 30 a 49 anos e trabalham em empresas privadas, a grande maioria das respostas (93) sobre suas motivações apresenta a flexibilidade de horário, seguido dos valores dos cursos, com 74 respostas, 
o que também caracteriza a amostra que possui uma renda de 1 a 3 salários. O cruzamento também demonstra a promoção e ascensão profissional com 35 respostas, corroborando o interesse dos estudantes em se qualificarem para o mercado de trabalho.

A Tabela 2 demonstra o cruzamento dos dados em relação aos fatores motivacionais e a faixa etária dos respondentes.

Tabela 2: Fatores motivacionais x Faixa etária

\begin{tabular}{|l|c|c|c|c|c|}
\hline \multirow{2}{*}{\multicolumn{1}{|c|}{ Fatores Motivacionais }} & \multicolumn{5}{c|}{ Faixa etária } \\
\cline { 2 - 6 } & $<18$ & 18 a 29 & 30 e 49 & 50 e 69 & Total \\
\hline Flexibilidade de Horários & 1 & 34 & 54 & 4 & 93 \\
\hline Valores dos cursos & 1 & 29 & 42 & 2 & 74 \\
\hline Promoção profissional & 0 & 12 & 21 & 2 & 35 \\
\hline Tempo de duração do curso & 1 & 10 & 18 & 3 & 32 \\
\hline Realização profissional & 0 & 14 & 18 & 0 & 32 \\
\hline Realização pessoal & 0 & 11 & 19 & 1 & 31 \\
\hline Tempo & 0 & 8 & 15 & 0 & 23 \\
\hline Prestígio da Instituição & 0 & 7 & 13 & 1 & 21 \\
\hline Localização do PAP & 0 & 5 & 13 & 1 & 19 \\
\hline Concluir os estudos & 1 & 4 & 9 & 0 & 14 \\
\hline Gostar de estudar sozinho & 0 & 7 & 4 & 2 & 13 \\
\hline Dinheiro & 0 & 2 & 5 & 0 & 7 \\
\hline Filhos/Família & 0 & 1 & 6 & 0 & 7 \\
\hline Relações dentro da Instituição & 0 & 0 & 3 & 0 & 3 \\
\hline Simplicidade do local & 0 & 0 & 0 & 0 & 0 \\
\hline Conhecer novas pessoas & 0 & 0 & 0 & 0 & 0 \\
\hline
\end{tabular}

Fonte: Dados da pesquisa, 2019.

Saber quem é o estudante do PAP, o que pensa, em que acredita, quais os seus julgamentos acerca de si mesmo e dos outros, qual será a sua posição na escala social, a idade, a renda, o estilo de vida, bem como a reação dele aos estímulos presentes no momento da decisão em fazer o curso, são fundamentais na busca incessante da compreensão desses estudantes. Os estudantes do PAP deixam claro que suas motivações estão ligadas às pressões da sociedade moderna, principalmente das relações de trabalho. É nesse contexto que a modalidade de ensino EaD, com sua flexibilidade, torna-se a peça-chave que leva aos fatores motivacionais, estimulando a disseminação de conhecimento.

\subsection{Fatores motivacionais que influenciam os estudantes do PAP}

\subsubsection{Fatores pessoais}

Os fatores pessoais estão ligados aos momentos e vivências em que as pessoas integram e que culminam em interferir nos seus hábitos e decisões (MOURA,2017). Portanto, quando a maioria dos estudantes se declarou solteiro, com uma idade superior a 30 anos, demonstraram que a família tradicional composta por marido, esposa e dois filhos está presente em um percentual muito menor dos lares do que no 
passado. Adicionalmente, estágios de ciclo de vida são mais importantes para a análise dessas motivações. Esses estágios fazem parte dos fatores pessoais, já que estão intrinsecamente ligados à personalidade, autoimagem, estilo de vida e valor (TEIXEIRA, 2010). Dessa forma, os estudantes receberam um conjunto de afirmativas sobre a escolha do curso.

A análise dos dados revelou que grande parte dos estudantes (43\%) concordou totalmente com a afirmação de que era seu sonho estudar o curso escolhido, o que envolve uma grande dose de motivação pessoal. Um percentual de $47 \%$ concordou totalmente que a escolha do curso foi por já estarem trabaIhando na área. $42 \%$ dos estudantes concordaram totalmente que querem se formar na área do curso escolhido, para ter um salário melhor. Um percentual de 37\% discordou totalmente da afirmação de que ainda não estão certos se vão trabalhar na área do curso escolhido. $43 \%$ dos estudantes discordaram totalmente da afirmação de que já possuem outra formação na área do curso escolhido. A média predominante na análise é que 35\% da amostra concordaram totalmente com as afirmativas apresentadas.

A Tabela 3 representa os números da pesquisa e seus percentuais.

Tabela 3: Fatores pessoais dos estudantes

\begin{tabular}{|l|c|c|c|c|c|}
\hline $\begin{array}{l}\text { Quanto ao curso que você } \\
\text { escolheu cursar }\end{array}$ & $\begin{array}{c}\text { Discordo } \\
\text { totalmente }\end{array}$ & $\begin{array}{c}\text { Discordo } \\
\text { parcialmente }\end{array}$ & Indiferente & $\begin{array}{c}\text { Concordo } \\
\text { parcialmente }\end{array}$ & $\begin{array}{c}\text { Concordo } \\
\text { totalmente }\end{array}$ \\
\hline $\begin{array}{l}\text { Era meu sonho estudar } \\
\text { sobre este curso }\end{array}$ & $7,92 \%$ & $3,96 \%$ & $15,84 \%$ & $28,71 \%$ & $43,56 \%$ \\
\hline $\begin{array}{l}\text { Escolhi esse curso, pois } \\
\text { trabalho na área }\end{array}$ & $13,86 \%$ & $3,96 \%$ & $10,89 \%$ & $23,76 \%$ & $47,52 \%$ \\
\hline $\begin{array}{l}\text { Quero me formar na área } \\
\text { para ter salário melhor }\end{array}$ & $9,90 \%$ & $6,93 \%$ & $14,85 \%$ & $25,74 \%$ & $42,57 \%$ \\
\hline $\begin{array}{l}\text { Ainda não estou certo se } \\
\text { vou trabalhar na área }\end{array}$ & $36,63 \%$ & $16,83 \%$ & $14,85 \%$ & $18,81 \%$ & $12,87 \%$ \\
\hline $\begin{array}{l}\text { Já possuo outra formação } \\
\text { na área }\end{array}$ & $43,56 \%$ & $5,94 \%$ & $8,91 \%$ & $12,87 \%$ & $28,71 \%$ \\
\hline Média & $22,38 \%$ & $7,52 \%$ & $13,07 \%$ & $21,98 \%$ & $35,05 \%$ \\
\hline
\end{tabular}

Fonte: Dados da pesquisa, 2019.

O que, em suma, vai ao encontro do pensamento de que o estado final desejado é motivado por um objetivo. Objetivos são os resultados buscados pelo comportamento motivado. Todo comportamento é orientado para objetivos (SCHIFFMAN; KANUK, 2000). Portanto, quando os estudantes concordam totalmente que "era meu sonho estudar sobre este curso", eles discordam totalmente que "ainda não estou certo se vou trabalhar na área", demonstrando que a motivação inicial precisa corresponder com um objetivo final para ser aceita.

\subsubsection{Fatores psicológicos}

Para Kotler e Keller (2006), os fatores psicológicos são: motivação, aprendizagem, crenças, atitudes e percepção. O principal aspecto desse fator é a aprendizagem, que influencia o comportamento do indivíduo. A aprendizagem consiste em mudanças no comportamento de uma pessoa, decorrentes da experiência. Grande parte do comportamento humano é aprendido. Os teóricos da aprendizagem acreditam que ela nasce da interação entre impulsos, estímulos, sinais, respostas e reforços. A dedicação aos estudos como fator motivacional está relacionada com essas interações. Quanto à dedicação ou não-dedicação aos estudos, os estudantes demonstram suas atitudes. Atitudes são predisposições aprendidas para 
responder a um objeto ou uma classe de objetos de forma consistentemente favorável ou desfavorável (SHETH, 2001), e, dessa forma, mudar seu comportamento.

Dos estudantes entrevistados, 30\% concordaram parcialmente que estudam diariamente no mínimo 1 hora. $41 \%$ dos estudantes concordaram parcialmente que estudam aos finais de semana, feriados ou folgas. Mais de $50 \%$ dos estudantes discordaram totalmente que estudam apenas para apresentações ou quando vão ao polo. Discordaram totalmente, $45 \%$ dos estudantes com a afirmação que estudam somente para as provas presenciais. E $50 \%$ dos estudantes discordaram totalmente que estudam somente ao fazer as avaliações on-line. A média predominante foi de 35\%, em que a amostra discordou totalmente das afirmações, o que demonstra que os estudantes se dedicam às atividades propostas, não visando somente serem aprovados, mas efetivando seu aprendizado.

A Tabela 4 representa todos os dados em percentuais, bem como suas médias determinantes.

Tabela 4: Fatores psicológicos dos estudantes

\begin{tabular}{|l|c|c|c|c|c|}
\hline \multicolumn{1}{|c|}{$\begin{array}{c}\text { Quanto à sua dedicação } \\
\text { aos estudos }\end{array}$} & $\begin{array}{c}\text { Discordo } \\
\text { totalmente }\end{array}$ & $\begin{array}{c}\text { Discordo } \\
\text { parcialmente }\end{array}$ & Indiferente & $\begin{array}{c}\text { Concordo } \\
\text { parcialmente }\end{array}$ & $\begin{array}{c}\text { Concordo } \\
\text { totalmente }\end{array}$ \\
\hline $\begin{array}{l}\text { Estudo diariamente, no } \\
\text { mínimo, uma hora por dia }\end{array}$ & $21,78 \%$ & $17,82 \%$ & $13,86 \%$ & $29,70 \%$ & $16,83 \%$ \\
\hline $\begin{array}{l}\text { Estudo aos finais de } \\
\text { semana, feriados ou folgas }\end{array}$ & $6,93 \%$ & $10,89 \%$ & $12,87 \%$ & $41,58 \%$ & $27,72 \%$ \\
\hline $\begin{array}{l}\text { Estudo apenas para } \\
\text { apresentações ou quando } \\
\text { vou ao polo }\end{array}$ & $50,50 \%$ & $11,88 \%$ & $15,84 \%$ & $15,84 \%$ & $5,94 \%$ \\
\hline $\begin{array}{l}\text { Estudo somente para as } \\
\text { provas presenciais }\end{array}$ & $45,54 \%$ & $13,86 \%$ & $10,89 \%$ & $19,80 \%$ & $9,90 \%$ \\
\hline $\begin{array}{l}\text { Estudo somente ao fazer } \\
\text { as avaliações on-line }\end{array}$ & $50,50 \%$ & $14,85 \%$ & $9,90 \%$ & $16,83 \%$ & $7,92 \%$ \\
\hline Média & $35,05 \%$ & $13,86 \%$ & $12,67 \%$ & $24,75 \%$ & $13,66 \%$ \\
\hline
\end{tabular}

Fonte: Dados da pesquisa, 2019.

A aprendizagem só é efetivada por meio da ação (ou seja, dedicação ou não aos estudos). Assim, quando as pessoas agem, elas aprendem. A aprendizagem, para Engel, Blackwell e Miniard (2013), é a ação pela qual a experiência resulta em mudanças no que tange ao conhecimento e ao comportamento.

\subsubsection{Fatores de mercado}

Com o avanço dos meios de transporte e das novas tecnologias, o estudante deseja estabelecer trocas e relacionamentos no momento que lhe convém e onde desejar (TEIXEIRA, 2010). Essa abordagem de mundo globalizado faz parte dos fatores de mercado: tudo o que for externo ao estudante e influencia o seu estado motivacional precisa ser analisado com afinco. Dessa maneira, as dificuldades externas, como fatores de mercado, foram abordadas como requisitos para os estudantes darem continuidade aos estudos. As influências externas determinam sobremaneira o comportamento dos estudantes, influenciando em suas motivações, escolhas e decisões (COSTA et al., 2010).

Dentro do grupo de afirmações, 56\% dos estudantes discordaram totalmente que o deslocamento ao PAP seria uma dificuldade externa. Mais de $61 \%$ também discordaram totalmente que o acesso a computador ou internet fosse uma dificuldade externa. Cerca de $37 \%$ discordaram totalmente de que a situação 
financeira seria uma dificuldade externa. 30\%, que seus horários de trabalho estariam no grupo de dificuldades externas. E 54\% discordaram totalmente de que a dificuldade na adaptação com o AVA seria uma dificuldade externa. A média predominante nessas afirmativas foi que $48 \%$ da amostra discordaram totalmente das afirmações propostas como fatores de dificuldades externas, o que demonstra que os estudantes identificaram que o PAP está próximo de suas casas e que eles possuem recursos tecnológicos para estudarem.

A Tabela 5 representa todos os dados em percentuais, bem como suas médias determinantes.

Tabela 5: Fatores mercadológicos dos estudantes

\begin{tabular}{|l|c|c|c|c|c|}
\hline $\begin{array}{c}\text { Quanto às dificuldades } \\
\text { externas que você enfrenta } \\
\text { para permanecer estudando }\end{array}$ & $\begin{array}{c}\text { Discordo } \\
\text { totalmente }\end{array}$ & $\begin{array}{c}\text { Discordo } \\
\text { parcialmente }\end{array}$ & Indiferente & $\begin{array}{c}\text { Concordo } \\
\text { parcialmente }\end{array}$ & $\begin{array}{c}\text { Concordo } \\
\text { totalmente }\end{array}$ \\
\hline $\begin{array}{l}\text { Deslocamento ao polo de } \\
\text { apoio presencial }\end{array}$ & $56,44 \%$ & $10,89 \%$ & $16,83 \%$ & $9,90 \%$ & $5,94 \%$ \\
\hline $\begin{array}{l}\text { Acesso ao computador ou à } \\
\text { internet }\end{array}$ & $61,39 \%$ & $6,93 \%$ & $14,85 \%$ & $9,90 \%$ & $6,93 \%$ \\
\hline Financeiro & $36,63 \%$ & $15,84 \%$ & $19,80 \%$ & $19,80 \%$ & $7,92 \%$ \\
\hline Horário de trabalho & $29,70 \%$ & $16,83 \%$ & $15,84 \%$ & $20,79 \%$ & $16,83 \%$ \\
\hline Dificuldade com AVA & $54,46 \%$ & $17,82 \%$ & $13,86 \%$ & $8,91 \%$ & $4,95 \%$ \\
\hline Média & $47,72 \%$ & $13,66 \%$ & $16,24 \%$ & $13,86 \%$ & $8,51 \%$ \\
\hline
\end{tabular}

Fonte: Dados da pesquisa, 2019.

O fator de mercado é um fator intrínseco do ambiente em que o estudante está inserido. Segundo Steenkamp (1993, p. 402), esse fator possui como características as questões socioculturais e econômicas. Por isso, sua análise se torna fundamental, uma vez que o estudante não pode consumir os serviços do PAP sem o deslocamento até o mesmo ou sem os recursos das tecnologias da informação e comunicação.

\subsubsection{Fatores sociais}

De acordo com Kotler (1998), o fator social exerce a mais ampla e profunda influência sobre as pessoas, pois elas são profundamente conduzidas por seus grupos de referências, que as expõe a novos comportamentos e estilos de vida. Os grupos fazem pressões que podem afetar as escolhas. Os grupos também são influenciados por grupos de aspiração ou de ascensão (KOTLER; KELLER, 2006) que estão relacionados com as ambições pessoais de cada indivíduo. Schiffman e Kanuk (2000) afirmam que o ser humano possui necessidades que o motivam, tais como de autorrealização, de estima, de segurança e fisiológicas, assim como a percepção e as atitudes nos mais diversos comportamentos, todos relacionados com as interações sociais. Os estudantes foram analisados em como os fatores sociais motivaram sua escolha pelo ensino a distância.

A escala contou com um conjunto de 14 afirmativas; as 3 afirmativas que obtiveram o maior número de respostas foram: $57 \%$ dos estudantes concordaram totalmente que escolheram a EaD por que gostariam de "estudar de forma que eu gerencio o meu tempo". Já 52\% concordaram totalmente que a flexibilidade é o principal fator. Dos estudantes respondentes, $48 \%$ concordaram totalmente de que a "possibilidade de definir rotinas e metas de estudo" é um fator pessoal de escolha para a EaD. A média predominante nesse conjunto de afirmativas foi de 35\% para concordo totalmente, o que vai ao encontro de que os fatores pessoais ligados com a flexibilidade motivam muito mais os estudantes do que os grupos de referência ou de pressão na escolha pelo ensino EaD. Este resultado está ligado intimamente às relações de trabalho e à sociedade moderna de consumo. 
A Tabela 6 representa os dados em percentuais, bem como suas médias determinantes.

Tabela 6: Fatores sociais dos estudantes

\begin{tabular}{|c|c|c|c|c|c|}
\hline $\begin{array}{c}\text { O que motiva você a estudar } \\
\text { na modalidade EaD }\end{array}$ & $\begin{array}{l}\text { Discordo } \\
\text { totalmente }\end{array}$ & $\begin{array}{c}\text { Discordo } \\
\text { parcialmente }\end{array}$ & Indiferente & $\begin{array}{c}\text { Concordo } \\
\text { parcialmente }\end{array}$ & $\begin{array}{l}\text { Concordo } \\
\text { totalmente }\end{array}$ \\
\hline Era meu sonho pessoal & $30,69 \%$ & $9,90 \%$ & $23,76 \%$ & $18,81 \%$ & $6,83 \%$ \\
\hline Influência familiar & $46,53 \%$ & $4,95 \%$ & $25,74 \%$ & $14,85 \%$ & $7,92 \%$ \\
\hline Questões de trabalho & $10,89 \%$ & $2,97 \%$ & $8,91 \%$ & $36,63 \%$ & $40,59 \%$ \\
\hline Almejo um salário melhor & $10,89 \%$ & $4,95 \%$ & $15,84 \%$ & $25,74 \%$ & $42,57 \%$ \\
\hline Almejo uma carreira estável & $7,92 \%$ & $4,95 \%$ & $18,81 \%$ & $28,71 \%$ & $39,60 \%$ \\
\hline $\begin{array}{l}\text { Melhorar a comunicação e } \\
\text { escrita }\end{array}$ & $15,84 \%$ & $4,95 \%$ & $23,76 \%$ & $29,70 \%$ & $25,74 \%$ \\
\hline Novo estilo de vida & $14,85 \%$ & $2,97 \%$ & $22,77 \%$ & $31,68 \%$ & $27,72 \%$ \\
\hline Flexibilidade & $3,96 \%$ & $2,97 \%$ & $11,88 \%$ & $28,71 \%$ & $52,48 \%$ \\
\hline $\begin{array}{l}\text { Vontade de aprender em } \\
\text { ambiente virtual }\end{array}$ & $12,87 \%$ & $2,97 \%$ & $23,76 \%$ & $39,60 \%$ & $20,79 \%$ \\
\hline $\begin{array}{l}\text { Possibilidade de } \\
\text { autoaprendizagem }\end{array}$ & $5,94 \%$ & $1,98 \%$ & $9,90 \%$ & $48,51 \%$ & $33,66 \%$ \\
\hline $\begin{array}{l}\text { Estudar de forma que eu } \\
\text { gerencie meu tempo }\end{array}$ & $1,98 \%$ & $0,99 \%$ & $5,94 \%$ & $33,66 \%$ & $57,43 \%$ \\
\hline $\begin{array}{l}\text { Gerenciar meu nível } \\
\text { de estresse }\end{array}$ & $11,88 \%$ & $3,96 \%$ & $17,82 \%$ & $38,61 \%$ & $27,72 \%$ \\
\hline $\begin{array}{l}\text { Possibilidade de definir } \\
\text { minhas rotinas e metas } \\
\text { de estudo }\end{array}$ & $2,97 \%$ & $0,99 \%$ & $8,91 \%$ & $38,61 \%$ & $48,51 \%$ \\
\hline Responsabilidade & $1,98 \%$ & $1,98 \%$ & $14,85 \%$ & $35,64 \%$ & $45,54 \%$ \\
\hline Média & $12,80 \%$ & $3,68 \%$ & $16,62 \%$ & $32,10 \%$ & $34,80 \%$ \\
\hline
\end{tabular}

Fonte: Dados da pesquisa, 2019.

A filiação e a interação social representam, talvez, os traços mais diferenciadores da condição humana, e o grupo constitui a base de toda a vida em sociedade (KARSAKLIAN, 2008). Embora as afirmações apresentem perguntas de organização pessoal, elas se ligam aos grupos. Os estudantes da modalidade EaD não estão isolados de suas relações e influências, e quando motivados por metas, tempo, responsabilidade e até mesmo estresse, eles são influenciados por interações impostas pela sociedade, e a sociedade nada mais é que a associação de pessoas que se relacionam entre si.

\subsubsection{Fatores culturais}

Os hábitos de estudo modificaram-se substancialmente nas últimas décadas com o avanço da internet, formando uma nova cultura. A influência da cultura sobre os atos humanos é hoje amplamente reconhecida, e grande parte das abordagens avançadas sobre o comportamento integra, de uma forma ou de outra, o fator cultural (TEIXEIRA, 2010). Nesse caso, foi utilizada uma análise de fatores culturais contemporâneos para analisar os estudantes. Na afirmativa de falta de apoio na empresa onde trabalho, $41 \%$ dos estudantes discordaram totalmente. Quando questionados sobre a afirmativa de falta de habilidade para usar o AVA como fator cultural, 57\% dos estudantes discordaram totalmente. Em relação a dificuldades econômico-financeiras, 39\% dos estudantes discordaram totalmente. Também discordaram totalmente 
de que falta de tempo seria um fator de cultura moderna, 30\% dos estudantes. Já $44 \%$ dos estudantes discordaram totalmente de que o sentimento de isolamento durante o curso é um fator cultural para a EaD. A falta de momentos presenciais de debate com colegas gerou $35 \%$ de respostas dos estudantes que discordaram totalmente dessa afirmativa.

Sendo assim, 41\% dos estudantes do PAP discordaram totalmente com o grupo de afirmativas sobre os fatores para estudarem na EaD e no PAP. Estes resultados demonstram que a EaD é um sistema de valores que exprimem uma nova interação cultural e seu modo de funcionamento desejado e inserido no cotidiano (TEIXEIRA, 2010).

A Tabela 7 representa todos os dados amostrais em porcentagem, bem como suas médias predominantes.

Tabela 7: Fatores culturais dos estudantes

\begin{tabular}{|l|c|c|c|c|c|}
\hline \multicolumn{1}{|c|}{$\begin{array}{c}\text { O que desmotiva você a } \\
\text { estudar na modalidade EaD }\end{array}$} & $\begin{array}{c}\text { Discordo } \\
\text { totalmente }\end{array}$ & $\begin{array}{c}\text { Discordo } \\
\text { parcialmente }\end{array}$ & Indiferente & $\begin{array}{c}\text { Concordo } \\
\text { parcialmente }\end{array}$ & $\begin{array}{c}\text { Concordo } \\
\text { totalmente }\end{array}$ \\
\hline $\begin{array}{l}\text { Falta de apoio na empresa } \\
\text { onde trabalho }\end{array}$ & $41,58 \%$ & $7,92 \%$ & $29,70 \%$ & $11,88 \%$ & $8,91 \%$ \\
\hline $\begin{array}{l}\text { Falta de habilidade para } \\
\text { usar o AVA }\end{array}$ & $57,43 \%$ & $10,89 \%$ & $21,78 \%$ & $5,94 \%$ & $3,96 \%$ \\
\hline $\begin{array}{l}\text { Dificuldades econômico- } \\
\text { financeiras }\end{array}$ & $38,61 \%$ & $13,86 \%$ & $23,76 \%$ & $13,86 \%$ & $9,90 \%$ \\
\hline Falta de tempo & $29,70 \%$ & $14,85 \%$ & $15,84 \%$ & $20,79 \%$ & $18,81 \%$ \\
\hline $\begin{array}{l}\text { Sentimento de isolamento } \\
\text { durante o curso }\end{array}$ & $44,55 \%$ & $10,89 \%$ & $22,77 \%$ & $10,89 \%$ & $10,89 \%$ \\
\hline $\begin{array}{l}\text { Falta de momentos } \\
\text { presenciais de debates } \\
\text { com colegas }\end{array}$ & $34,65 \%$ & $7,92 \%$ & $24,75 \%$ & $17,82 \%$ & $14,85 \%$ \\
\hline Média & $41,09 \%$ & $11,06 \%$ & $23,10 \%$ & $13,53 \%$ & $11,22 \%$ \\
\hline
\end{tabular}

Fonte: Dados da pesquisa, 2019.

Blackwel, Miniard e Engel (2013, p. 326) salientam que "a cultura tem sido definida como um conjunto de padrões de comportamentos sociais que são transmitidos simbolicamente pela linguagem e por outros meios para membros de uma sociedade". Nesse sentido, os valores culturais da sociedade moderna perpassam novas experiências, englobando o mercado de trabalho, as novas tecnologias, a economia, o tempo disponível e até mesmo a falta de convívio social. Dessa forma, analisar os estudantes sob a luz da cultura moderna individualiza o processo, verificando sua perspectiva em relação às mudanças do mundo e às necessidades que surgiram com as mesmas.

\section{Conclusão}

O presente artigo procurou traçar o perfil demográfico e analisar os fatores motivacionais dos estudantes de um polo de apoio presencial de uma instituição de ensino EaD. Seu objetivo principal consistiu em realizar uma pesquisa investigando esses estudantes. O contexto em que a pesquisa foi realizada deu-se em virtude do grande crescimento da EaD e a necessidade de analisar esse fenômeno pela óptica do perfil desses estudantes, analisando sua idade, sexo, local de trabalho e renda. A análise do perfil demográfico demonstrou que o polo de apoio presencial é constituído por estudantes com idade entre 30 e 49 anos, do gênero masculino, solteiros, funcionários de empresa privada com renda de até três salários-mínimos. A maioria das respostas sobre suas motivações refere-se à flexibilidade de horário, seguido dos valores 
dos cursos, promoção e ascensão profissional e tempo de duração do curso - o que confirma em estudos realizados e descritos na análise feita: que os estudantes buscam alternativas para a manutenção dos seus postos de trabalho e crescimento profissional.

A pesquisa também analisou os estudantes com base nos fatores motivacionais. Os fatores que influenciam comportamentos são diversos e contemplam os fatores culturais, sociais, pessoais, psicológicos e de mercado. Quando perguntados quanto ao curso escolhido, os estudantes afirmaram que o motivo foi por trabalharem na área, confirmando que as relações de trabalho se mostram majoritárias em termos de motivações pessoais. Quanto à sua dedicação aos estudos, os estudantes responderam não estudarem apenas para apresentações de trabalhos ou quando vão ao polo, o que psicologicamente demonstra que eles buscam a efetivação do aprendizado, principal fator para continuarem consumindo os serviços do PAP. Os estudantes disseram possuir acesso ao computador e à internet para realizarem suas atividades acadêmicas, mostrando que a internet mudou paradigmas e já não pode ser considerada uma dificuldade externa ou mercadológica para quem busca o aperfeiçoamento. A flexibilidade novamente aparece como motivação para os estudantes ingressarem na $\mathrm{EaD}$, demonstrando que a modalidade existe às margens das relações sociais. Os estudantes afirmaram ter total habilidade para utilizar o AVA, corroborando que a cultura da internet e do mundo contemporâneo e faz presente e já são aprendidos como um rito ou hábito do dia a dia. Assim, pode-se concluir que o fator que mais predominantemente se destaca nessa relação é o fator social, que integra no seu grupo de afirmações a flexibilidade dessa modalidade de ensino, sendo presente em diversas interações durante a pesquisa.

Nesse caso, os alunos não se sentem isolados, pois possuem maior tempo para outras atividades e interações sociais, inclusive interagindo com a tecnologia. Contudo, a maior contribuição deste trabalho está no aspecto pedagógico, uma vez que o conhecimento das características do estudante é condição sine qua non para o desenvolvimento de um planejamento pedagógico pertinente à realidade do estudante. Nesse sentido, entende-se que o estudo realizado sobre o estudante matriculado no polo de apoio presencial pode trazer subsídios importantes para o estabelecimento de novos mecanismos de ensino por parte dos coordenadores pedagógicos. Ao findar o estudo, acredita-se que novas pesquisas possam ser realizadas, a fim de contribuir ainda mais para a busca de objetivos. Sendo assim, recomenda-se que, além deste, o estudo seja aplicado novamente dentro de certo período de tempo no mesmo polo de apoio presencial, com o propósito de comparar os resultados obtidos e efetuar as devidas mudanças em relação à pesquisa.

\section{Referências}

ASSUMPÇÃO, G. S.; HAMADA, P. C.; CASTRO, A. C.; Análise do perfil dos alunos do primeiro curso de EAD em engenharia de produção em instituições de ensino superior pública. Revista Produção Online, Florianópolis, Santa Catarina, v. 18, n 2. p. 404-423, ago 2018.

BERNI, D. A.; FERNANDEZ, B. P. M. Métodos e técnicas de pesquisa - modelando as ciências empresariais. Saraiva, São Paulo, 2012, 440p.

BINOTTO, S. et al. Os fatores de influência no comportamento do consumidor: um estudo em uma cooperativa agrícola do RS. RGC, v. 01, n.2, , p. 13-26, jul 2014.

BRASIL. Instituto Nacional de Estudos e Pesquisas Educacionais Anísio Teixeira - INEP. Dados do Censo da Educação Superior. Brasília, mar 2019. Disponível em: http://inep.gov.br/artigo/-/asset publisher/ B4AQV9zFY7Bv/content/dados-do-censo-da-educacao-superior. Acesso em: 08 fev. 2020.

BRASIL. Instituto Nacional de Estudos e Pesquisas Educacionais Anísio Teixeira - INEP. Dados do Censo da Educação Superior. Brasília, mar 2014. Disponível em: http://inep.gov.br/artigo/-/asset_publisher// IYIsGMAMKWIcontent/dados-do-censo-da educacao-superior. Acesso em: 09 fev. 2020. 
COSTA, A. C. M. et al. Análise dos fatores motivacionais e determinantes no processo de decisão de compra do consumidor turístico no entorno do Parque Nacional da Serra da Canastra na região de São Roque de Minas (MG). Revista Brasileira de Ecoturismo, São Paulo, v. 3, n. 2, p. 215-234, dez 2010.

ENGEL, J. F.; BLACKWELL, R. D.; MINIARD, P. W. Comportamento do consumidor. São Paulo: Cengage Learning, 2013, 644p.

FRANCO, M. L. P. B. Estudo de caso, no falso conflito entre pesquisa qualitativa e pesquisa quantitativa. Inter-Ação, Ribeirão Preto, v. 14, n. 1, p. 1-6, jan 1990.

GIL, A. C. Como elaborar projetos de pesquisa. 3. ed. São Paulo: Atlas, 1996, 630p.

GONÇALVES, H. J.; Fidelização de clientes. Programa de Pós-Graduação em Administração da Universidade Federal do Rio Grande do Sul, Porto Alegre, 61f. 2007.

HAWKINS, D.I.; MOTHERSBAUGH, D. L.; BEST, R. J. Comportamento do consumidor: construindo a estratégia de marketing. 10. ed.. Rio de Janeiro: Elsevier, 2007, 528p.

IRAOSSI, G. The power of survey design: a user's guide for managing surveys, interpreting results, and influencing respondents. The World Bank, Washington, D.C., 2006, 282p.

KARSAKLIAN, E. Comportamento do consumidor. São Paulo, Atlas, 2008, 303p.

KOTLER, P. Administração de marketing: análise, planejamento, implementações e controle. São Paulo, Atlas, 1998, 896p.

KOTLER, P.; ARMSTRONG, G. Princípios de marketing. SP: Person Prentice Hall, 2007, 800p.

KOTLER, P.; KELLER, K. L. Administração de marketing. São Paulo: Pearson, 2006, 896p.

MALHORTA, N. K. Pesquisa de marketing: uma orientação aplicada. 3. ed. Porto Alegre: Bookman, 2001, 768p.

MCCARTHY, E. J.; PERREAULT, W. D.; Marketing Essencial. SP: Atlas S.A., 1997, 396p.

MOLEIRINHO, M. V. C. D.; MALHEIRO, S. S. ; MORGADO, L. M. G. Contributo exploratório para uma abordagem digital inclusiva: o caso das universidades de ensino a distância. Portugal, Europa: Publicações Faculdades de Letras Universidade de Lisboa. Trabalho apresentado no Congresso realizado na Universidade de Lisboa de 17 a 19 de abril de 2013.

MOURA, R. G. Comportamento do consumidor: a influência da embalagem no processo de decisão de compra das mulheres na aquisição de cosméticos nos supermercados. REA-Revista Eletrônica de Administração, v. 16, n. 1, p. 4-24, mar 2017.

PETERS, O. The iceberg has not melted: further reflections on the concepto of industrialization and distance teaching. Open Learning. v. 4, n. 3, p. 3-8, ago 1989.

RICARDO, J. S. Múltiplos enfoques sobre as competências na Educação a Distância: uma problematização necessárias. EaD em Foco, v. 9, n. 1, e731, 2019.

ROLIM, A. T.; SCARAMUZZA, B. C. Aprendizagem significativa em ambientes virtuais de aprendizagem. Revista do Programa de Pós-graduação em Educação - Mestrado - Universidade do Sul de Santa Catarina, v. 10 n. especial, p. 182-195, dez 2016.

RUSSO, M. Inovação no ensino da biblioteconomia no Brasil: implantação do bacharelado na modalidade de Educação a distância. Inf. \& Soc.: Est., v.26, n. 1, p. 21-35, mar 2016. 
SCHIFFMAN, L. G.; KANUK, L. L. Comportamento do Consumidor. Rio de Janeiro: LTC - Livros Técnicos e Científicos, 2000, 475p.

SCHLIKMANN, R. et al. Fatores determinantes na opção do aluno pela modalidade a distância: um estudo nos cursos de graduação em administração das universidades catarinenses. Tese de Doutorado, Universidade Federal de Santa Catarina, Centro Sócio-Econômico. Programa de Pós-Graduação em Administração, 2008.

SCHINAIDER, A. D.; FAGUNDES, P. M.; SCHINAIDER, A. D. Comportamento do consumidor educacional: seu perfil e o processo de decisão de compra. Future Studies Research Journal. v. 8, n. 2, São Paulo, p. 144-164, jul 2016.

SHETH, J. N. O comportamento do cliente: indo além do comportamento do consumidor. São Paulo: Atlas, 2001, 795p.

SOARES, M. H. A.; ARDIGÓ, C. M.; MELO FILHO, M. E. S. Análise de qualidade do serviçO: um estudo entre a percepção do cliente e do guia de roteiros regionais do SESC - Santa Catarina, Brasil. RTA - Revista Turismo em Análise. v. 28 n. 3, São Paulo, p. 492-512, dez 2017.

SOUZA, L. B. Educação superior a distância: o perfil do novo aluno Sanfranciscano. Revista da Associação Brasileira de Educação a Distância, v. 11, n. 1, Minas Gerais, p. 21-33, mar 2012.

STEENKAMP, J. B. Food consumtion behavior. European Advances in Consumer Research, 1993.

SUN, P. C. et al. What drives a successful e-learning? Na empirical investigation of the critical factors influencing learner satisfaction. Computers \& Education, v. 50, n. 4, China, p. 1183-1202, dez 2008.

TEIXEIRA, J. C. I. Fatores que influenciam o comportamento do consumidor. 2009, 42f, Monografia de Pós-Graduação em Gestão estratégica de vendas e negociação, Universidade Cândido Mendes, Rio de Janeiro, 2010.

VERGARA, S. C. Projetos e relatórios de pesquisa em Administração. 10. ed. São Paulo: Atlas, 2009, 104p. 